\title{
Thermophysiological, haematological, biochemical and behavioural stress responses of sheep transported on road
}

M. Pascual-Alonso, G. C. Miranda-de la Lama, L. Aguayo-Ulloa, M. Villarroel, M. Mitchell and G. A. María

\section{Summary}

The study was conducted to evaluate the thermophysiological, haematological, biochemical and behavioural stress responses of sheep transported on road. A total of 44 Chamarita breed adult ewes were randomly allotted to one of two groups, one control group (untransported) and transported group (journey of 4 h), and blood stress indicators were measured 1 day before transport and at four time points post-transport $(0,4$ and $24 \mathrm{~h})$. Thermophysiological profiles of ewes were measured by temperature buttons (iButton Thermochron ${ }^{\circledR}$ ) and placed in intravaginal sponges. Direct observations, with a combination of scan and behaviour sampling, were carried out to collect information on individual behaviour and the time it took the ewes to drink water, eat and rest after returning to their pen respectively. Transported ewes lost approximately $1 \mathrm{~kg}$ live weight compared to controls and had higher body temperatures until $12 \mathrm{~h}$ post-transport. Cortisol, glucose, non-esterified fatty acid (NEFA) concentrations as well as the neutrophil-lymphocyte ratio (N/L) and other physiological indicators were higher immediately after unloading in transported ewes but mostly returned to normal after $4 \mathrm{~h}$, with complete recovery after $24 \mathrm{~h}$. Behavioural analysis post-transport demonstrated that transported ewes chose to eat before drinking and spent less time resting than controls in the first $3 \mathrm{~h}$ after unloading. The study demonstrates that transportation even under short-journey conditions induced behavioural, physiological and thermophysiological responses indicative of the induction of significant stress, leading to live weight shrinkage that may jeopardize farmer's incomes. Finally, results of this study validated the use of iButton Thermochron ${ }^{\circledR}$ data loggers for monitoring the stress response during transport.

Keywords transport, stress hyperthermia, iButton Thermochron ${ }^{\circledR}$, sheep

\section{Introduction}

Livestock transportation is an essential element of extensive production systems. Particularly for sheep, widely spread, pasture-based farming systems result in the need to move animals for a variety of reasons including breeding, grazing opportunities or sale (Fisher et al., 2009; Liu et al., 2012). Sheep may be transported within properties, between properties, and between a property and markets, or to make best use of seasonal conditions (Jones and Tensen, 2009). The efficiency of animal transport, which can involve collecting from various farms, or queuing and unloading at the destination point, could improve when integrated with a dynamic planning process that takes into account road conditions, weather, traffic conditions, transport time and distance (Gebresenbet et al., 2011).

Even under favourable conditions, livestock are exposed to a range of potential stressors which may compromise their welfare, health and performance due to changes in the thermal micro-environment, weather conditions, social mixing, handling, withdrawal of feed and water, vibration and acceleration and associated fatigue, loading and unloading stress and injury, noise and environmental pollutants 
(Mitchell and Kettlewell, 2008; Miranda-de la Lama et al., 2014). Stressors are known to cause a shortlived increase in core body temperature or hyperthermia in ruminants (Proctor and Carder, 2015). They stimulate the sympathetic pathway of the autonomic nervous system and may alter the thermoregulatory set point (Pedernera-Romano et al., 2010), which can be a potential welfare indicator (Ingram et al., 2002). Rectal temperature has traditionally been used to measure the core temperature of animals, although miniature temperature data loggers have recently been employed to measure core temperature, while avoiding the potential stress of rectal measurement (which itself could induce a rise in body temperature; Piccione et al., 2014).

Recently, iButtons have been used to record body temperatures, especially in animals of all sizes, through surgical implantations, insertions into the gastrointestinal tract, ear canal or attachment to the animal's outer surface (Roznik and Alford, 2012). Thus, the impact of various stressors such as transportation can be determined by monitoring body temperature dynamics. However, little is known about the possible impacts of transport on the thermophysiological stress response in general in farm animals, and especially in sheep using miniature data loggers as non-invasive welfare indicator during transport. The authors of this study propose the application of the IBUTTON THERMOCHRON ${ }^{\circledR}$ as tool for measurement of intravaginal temperature in ewes to study the stress response during road transport. Additionally, numerous studies have investigated the effects of transport on sheep destined to slaughterhouses, but to our knowledge there are no reports concerning live journeys for productive reasons. The hypothesis of the current study is that the thermophysiological, haematological, biochemical and behavioural responses of transported sheep provide a sensitive indication of transport-level stress. As a result, basic information on ewes during road transport could contribute to improving the welfare and health aspects of transportation in live journeys. Therefore, the aim of this study was to evaluate the thermophysiological, haematological, biochemical and behavioural stress responses of sheep transported on road.

\section{Materials and methods}

The study was carried out in the Autonomous Community of Aragon, Spain, in June 2013 (summer), at the experimental farm (Animal Experimentation Service) of the University of Zaragoza (latitude $41^{\circ} 41^{\prime} \mathrm{N}$ ). This region is characterized by a Mediterranean continental dry climate with irregular rainfall, a broad temperature range and strong winds. Seasons are very marked with hot and dry summers (maximum $42{ }^{\circ} \mathrm{C}$; minimum $15{ }^{\circ} \mathrm{C}$ ) and cold and slightly humid winters (maximum $11{ }^{\circ} \mathrm{C}$; minimum $3{ }^{\circ} \mathrm{C}$ ), with broad thermal amplitudes. All animal procedures performed in this study were conducted under experimental licence from Animal Experimentation Ethics Committee of the University of Zaragoza.

\section{Subjects and study description}

Forty-four Chamarita adult ewes (average age 6.5 years), a Spanish breed, were used in this study and randomly divided into two pens with 22 ewes each, 2 weeks before transport (density $2 \mathrm{~m}^{2}$ per ewe). They were fed twice a day (08:00 and 15:00) with pellet concentrate (11.5 MJ metabolizable energy $/ \mathrm{kg}$ dry matter and $15.5 \%$ crude protein; approximately $0.3 \mathrm{~kg}$ per ewe), and lucerne chaff (Medicago sativa) ad libitum. The pen was equipped with a metallic water trough $(1.5 \times 0.60 \mathrm{~m})$ and two metallic feeders $(4.5 \times 0.80 \mathrm{~m}, 27 \mathrm{~cm}$ per ewe $)$, and a lick stone for minerals. One group (pre-transport live weight $47.72 \pm 1.75 \mathrm{~kg}$ ) was transported on a livestock lorry in a route of $200 \mathrm{~km}$ or $4 \mathrm{~h}$ (including loading and unloading) and unloaded again at the same location while the controls were not transported. Control ewes (pre-transport live weight $47.64 \pm 1.75 \mathrm{~kg}$ ) were maintained in a neighbouring pen, but not within sight of the transported ewes to minimize possible social disturbance.

Road transport was carried out on public highways that were mostly straight and flat along the Ebro valley (minimum changes in altitude, $\leq 50 \mathrm{~m}$ ), with short periods on a dirt road. The average vehicle speed during the journey was $62 \mathrm{~km} / \mathrm{h}$, avoiding abrupt accelerations and decelerations. The weather conditions on the day of transport were sunny with a slight breeze (average temperature, $22.9^{\circ} \mathrm{C}$ ). The vehicle used was a livestock lorry $\left(\mathrm{NISSAN}^{\circledR}\right.$; model L35.09, 3.5 ton capacity; Avila, Spain) designed for sheep transport (two pens inside), with two axles and a rigid chassis, roof and with steel spring suspension. The vehicle had incorporated a loading ramp door with a maximum ramp angle of $26^{\circ}$. Loading density was $0.4 \mathrm{~m}^{2}$ per ewe [within the recommendations of the European Commission (2006)]. The floor of the vehicle was covered with straw, and no food or water was provided during transport. Air temperature and relative humidity were recorded every 15 min using Testo ${ }^{\circledR}$ data loggers (Testo $A G^{\circledR}$, Lenzkirch, Germany) positioned at sheep height on the livestock vehicle and on the 
experimental farm sheep (for control ewes). The temperature humidity index (THI) is calculated from air temperature and relative humidity using the following equation: $\quad \mathrm{THI}=($ Dry bulb temperature $\left.{ }^{\circ} \mathrm{C}\right)+\left(0.36 \times\right.$ dew point temperature $\left.{ }^{\circ} \mathrm{C}\right)+41.2$. The THI has been used since the early 1990s. It accounts for the combined effects of environmental temperature and relative humidity, and is a useful and easy way to assess the risk of heat stress (Miranda-de la Lama et al., 2014).

\section{Thermophysiological measurements}

The internal body temperature of transport and control ewes $(n=44)$ was measured by temperatureregistered buttons (DS1921G; IBUTTON THERMOCHRON ${ }^{\circledR}$ data loggers, Eclo, Leiria, Portugal) inside intravaginal sponges especially ordered without hormones (Sin$\operatorname{cropart}^{\circledR}$; Ceva Salud Animal SA, Barcelona, Spain), $24 \mathrm{~h}$ before transport. The IBUTTON THERMOCHRoN ${ }^{\circledR}$ are small (ca. $3 \mathrm{~g}$ ) data loggers that include a thermometer, a real time clock and a memory to collect up to 2048 data points. The buttons recorded the internal temperature every $1 \mathrm{~min}$ throughout the trial in transported and control ewes (from 2 h before loading until $24 \mathrm{~h}$ after unloading). EXPRESS-THERMO $2007^{\circledR}$ management software (Eclo, Leiria, Portugal) for IBUTTON THERMOCHRON ${ }^{\circledR}$ data loggers was used to analyse the ewe temperature changes during the study. Before the commencement of the experiments, data loggers were calibrated in a temperature-controlled water bath to $\pm 0.1{ }^{\circ} \mathrm{C}$ at approximately $5{ }^{\circ} \mathrm{C}$ increments over the range $5-40{ }^{\circ} \mathrm{C}$, against a mercury-in-glass thermometer traceable to a National Association of Testing Authorities (NATA) calibrated standard (Hilmer et al., 2010).

\section{Haematological and biochemical measurements}

Blood samples were taken from all ewes $(n=44)$ by jugular venepuncture with vacuum tubes the day before transport (BT), immediately after unloading (PT0), $4 \mathrm{~h}$ after transport (PT4) and $24 \mathrm{~h}$ post-transport (PT24). Two 10-ml tubes per animal were taken, with and without anticoagulant (EDTA-K3). Samples were kept on ice for a maximum of $2 \mathrm{~h}$ and taken to the laboratory for routine haematological measurements. EDTA plasma and serum were centrifuged at $3000 \mathrm{~g}$, at $4^{\circ} \mathrm{C}$ for $10 \mathrm{~min}$, and aliquots were frozen and kept at $-30{ }^{\circ} \mathrm{C}$ until analysis.

An automatic particle counter (Microcell counter F-800 and auto dilutor AD-260, both from Sysmex ${ }^{\mathrm{TM}}$, Toa Medical Electronics, Japan) was used to count red blood cells (RBC) and white blood cells (WBC) (number per $\left.\mathrm{mm}^{3}\right)$, haemoglobin $(\mathrm{g} / \mathrm{dl})$, haematocrit $(\%)$, platelets, mean corpuscular volume (MCV), mean corpuscular haemoglobin (MHC) and mean corpuscular haemoglobin concentration (MCHC). The leucocyte differential was estimated from blood swabs on clean slides. Staining was performed by the rapid panoptic method using dyes from Química Clinica Aplicada S.A. $\left(\mathrm{QCA}^{\circledR}\right.$, Tarragona, Spain). With an optic immersion microscope, we counted and identified 100 leucocytes per sample (neutrophils, lymphocytes, eosinophils, basophils and monocytes). The neutrophil-lymphocyte ratio (N/L) was used as an indicator of stress. Serum samples were used to determine the concentration of glucose (mg/dl, Ref. Glucose AE2-17), and the activity of creatine kinase (CK) (UI/L) (Ref. CK.NAC AE 1-13) using a multi-analyser $\mathrm{ACE}^{\circledR}$ (Clinical Chemistry System of the Alfa Wassermann, Woerden, the Netherlands) and reagents from Alfa Wassermann. The serum concentration of non-esterified fatty acid (NEFA) levels was analysed by an $\mathrm{ACE}^{\circledR}$ multi-analyser (Clinical Chemistry System of the Alfa Wassermann, Woerden, the Netherlands), with commercial kits (NEFA; C Ref. 994-75409 from Wako Chemicals, Richmond, VA, USA).

The concentration of cortisol was determined from plasma (K3-EDTA) by enzyme immunoassay using an 'in-house kit' (validated by Chacón et al., 2004). Each sample was determined in duplicate from $50 \mu \mathrm{l}$ of plasma. The mean of the duplicate was used as the result and expressed in nmol/l. Interand intra-assay coefficients of variation were $6 \%$ and $9 \%$ respectively. The concentration of lactate was determined using a Sigma Diagnostic kit (lactate no. 735-10) and a spectrophotometer (Lambda 5; Perkin Elmer, Waltham, MA, USA). The concentrations of phosphorus and calcium in plasma were measured colorimetrically by standard spectrometric techniques. Plasma total protein and urea concentrations were measured by continuous flow analysis (CFA) using an auto-analyser (Technicon Instruments Corporation ${ }^{\circledR}$, Tarrytown, NY, USA). The concentration of haptoglobin was determined by radial immunodiffusion in $1 \%$ agarose gels containing specific antisera.

\section{Behavioural and live weight measurements}

The two experimental groups were observed for $3 \mathrm{~h}$ immediately after unloading. Direct observations, with a combination of scan and behaviour sampling, were carried out to collect information on individual behaviour and the time it took the ewes to drink 
water, eat and rest after returning to their pen respectively. A platform with a seat $3 \mathrm{~m}$ above the ground was used to observe the ewes from a distance, always by the same trained observer. During the whole time of observation, scan sampling was carried out every 5 min (33 samples) to obtain information about the number of ewes lying down (ewe resting with eyes open or closed), eating (ewe with head inside the feeder trough), drinking (ewe with head inside the metallic water trough) and walking (ewe moving from one place to another). Live weight loss (shrinkage) was calculated as the live body weight of each ewe the day before transport (WB) minus the weight immediately after unloading (WA), using a portable digital weighing scale.

\section{Statistical analysis}

Data were analysed using the least squares methods of the generalized linear model procedure using SAS/ STAT (SAS, 1998), fitting a one-way model with a fixed effect of transport (two levels). The general representation of the model used was as follows: $\mathrm{y}=\mathrm{Xb}+\mathrm{e}$, where $\mathrm{y}$ was an $\mathrm{N} \times \mathrm{l}$ vector of records, $\mathrm{b}$ denoted the fixed effect in the model with the association matrix $\mathrm{X}$ and e was the vector of residual effects. The frequency rates at which the animals performed a behaviour (number of observations during the observation period) throughout the post-transport period were analysed using Kruskal-Wallis test. A probability of $\mathrm{p}<0.05$ values was considered statistically significant.

\section{Results}

The average micro-environmental temperature and relative humidity in the lorry during transport were $23.2( \pm 2.7){ }^{\circ} \mathrm{C}$ and $52.5( \pm 5.7) \%$ respectively. These values at the experimental farm during the transport and post-transport period were $22.9( \pm 3.1){ }^{\circ} \mathrm{C}$ and $51.4( \pm 8.3) \%$ respectively. The mean THI, during transport, was $83.3 \pm 1.4$ (max. 86.5 , min. 80.9 ), and at the experimental farm was $82.6 \pm 0.7$ (max. 84.4, min. 81.6).

\section{Thermophysiological measurements}

In general, transported ewes had a higher internal body temperature (measured by IBUTTON THERMOCHRON ${ }^{\circledR}$ data loggers), during the whole experiment until $12 \mathrm{~h}$ after the journey, when the temperature decreased below even the control animals. Within treatments, we found significant differences between moments in both groups $(\mathrm{p}<0.05)$. The control ewes showed inconsistent differences between moments. The transported ewes suffered a consistent increase in internal body temperature until a turning point between the end of the journey and unloading. Subsequently, they recovered to their initial values (Fig. 1).

\section{Haematological and biochemical measurements}

Transported ewes had slightly lower cortisol levels than controls the day before transport (Table 1), and

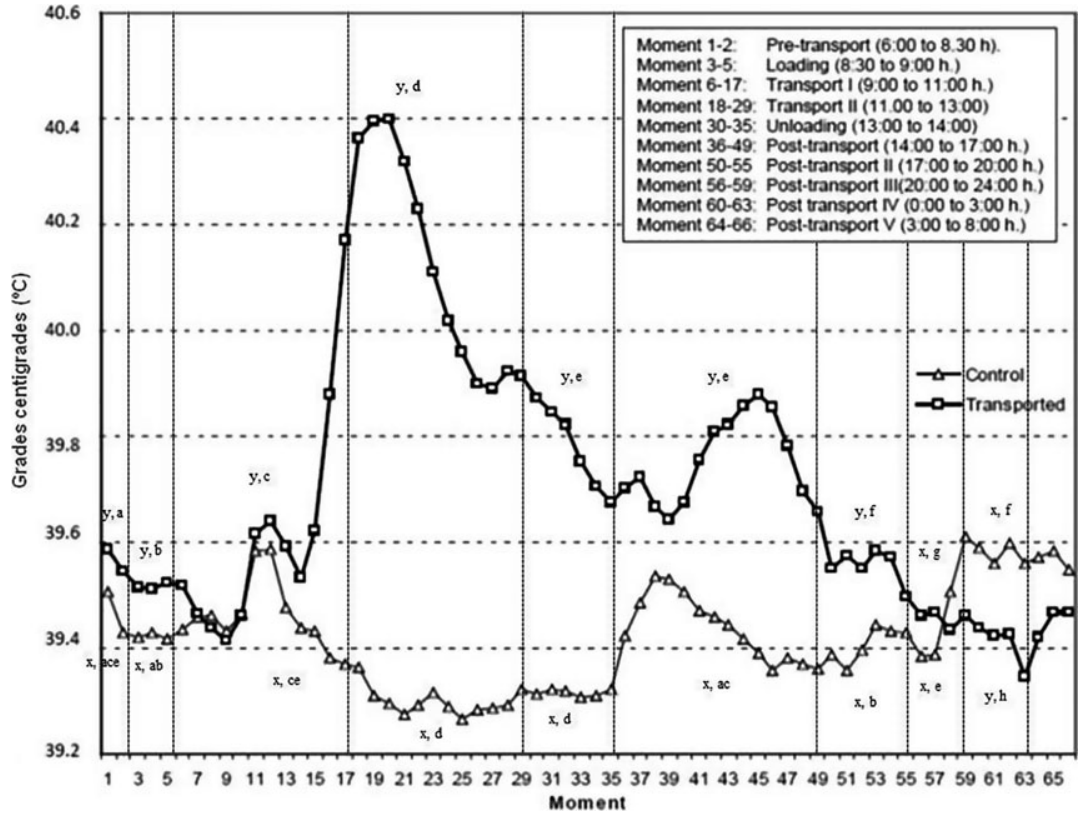

Fig. 1 Evolution of the least square means of the thermophysiological stress response profiles (core body temperature) in ewes transported and not transported (control) by road for $4 \mathrm{~h}$ (1441 data points per ewe). a, b, c, $d, e, f$ : different letters represent significant differences between moment within treatment. $x, y$ : different letters represent significant differences between treatment within moment. 
Table 1 Least square means ( \pm SE) of physiological stress variables in ewes subjected or not to $4 \mathrm{~h}$ of transport

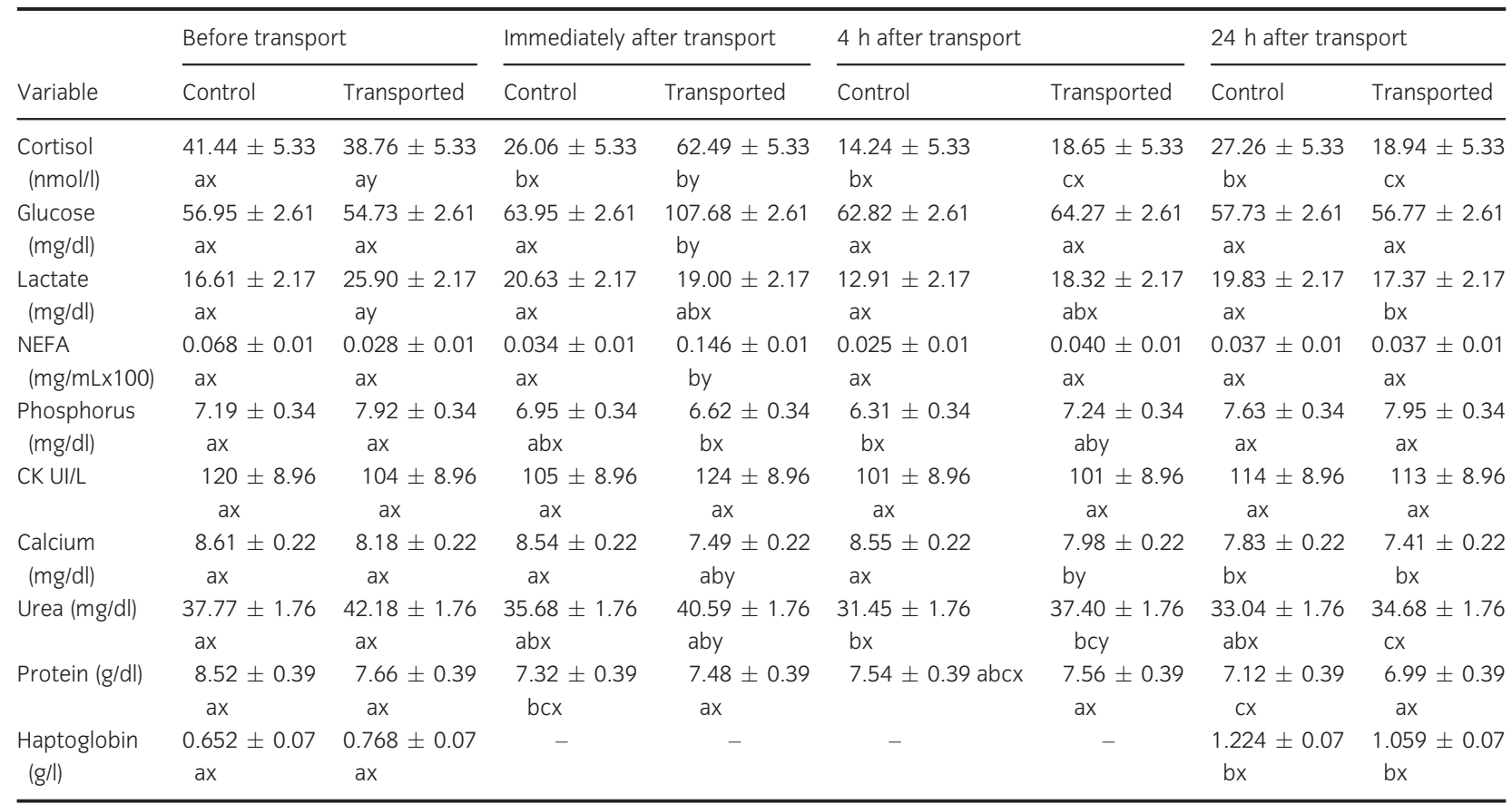

NEFA, non-esterified fatty acid; CK, creatinine kinase.

a,b,c: different letters represent significant differences between sampling moment within treatment (control or transported).

$\mathrm{x}, \mathrm{y}, \mathrm{z}$ : different letters represent significant differences between treatment within sampling moment (before transport; immediately after transport; $4 \mathrm{~h}$ after transport; $24 \mathrm{~h}$ after transport).

higher levels after unloading (139\% higher than controls), returning to control levels $4 \mathrm{~h}$ later $(p<0.05)$. Glucose and NEFA followed the same trend as cortisol, increasing immediately after transport $(68.4 \%$ and $329.4 \%$ higher than controls respectively; $\mathrm{p}<0.05$ ) and decreasing $4 \mathrm{~h}$ later. Lactate levels were more similar between transported ewes and controls (slightly higher in transported ewes the day before transport) and lowest $24 \mathrm{~h}$ after transport $(\mathrm{p}<0.05)$. The CK levels were not different between treatments $(p>0.05)$. Phosphorus values were significantly lower after unloading in transported ewes $(-14.7 \% ; \mathrm{p}<0.05)$. Calcium levels were lower after transport (PTO: $-14 \%$ and PT4: $-7 \% ; p<0.05)$. Urea levels were higher in the transport group compared to controls (PT0: $+14 \%$; PT4: $+18 \%$ and PT24: $+5 \% ; p<0.05)$. Protein levels were quite consistent in transported ewes and slightly higher in control ewes the day before transport $(p<0.05)$. Finally, haptoglobin had a similar tendency in both transported and controls, increasing at the end of the experimental period. After $24 \mathrm{~h}$, there were no significant differences between treatments in any of the parameters measured $(\mathrm{p}>0.05)$.
Regarding the haematological values (Table 2), MCV increased significantly while MCHC decreased at PT4 (p < 0.05). In transported ewes, neutrophils, eosinophils and the N/L ratio increased significantly at PTO but decreased to normal levels by $24 \mathrm{~h}$ post-transport $(p<0.05)$. Basophils and lymphocytes decreased at PTO, and WBC and platelet counts increased significantly $(p<0.05)$ after $24 \mathrm{~h}$. Differences between treatments were found before road transport, with higher MCV values in transported ewes $(p<0.05)$. Immediately after transport, eosinophil and lymphocyte counts were lower in transported ewes $(-420.4 \%$ and $-32.1 \%$ respectively; $p<0.05)$, while neutrophil counts and the N/L ratio were higher in transported ewes $(+65.9 \%$ and $+122.8 \%$ respectively; $\mathrm{p}<0.05)$. Four hours after transport, eosinophil and lymphocyte counts were still lower in transported ewes $(-216.9 \%$ and $-14.9 \%$ respectively; $p<0.05)$, while neutrophil counts and the N/L ratio were still higher in transported ewes $(+37 \%$ and $+56.6 \%$ respectively; $\mathrm{p}<0.05)$. After $24 \mathrm{~h}$, lymphocyte counts were lower in transported animals $(-9.8 \%$; $<<0.05)$, while neutrophil counts and the N/L ratio were still higher in transported ewes $(+19.1 \%,+33.9 \%$ respectively; $\mathrm{p}<0.05)$. 


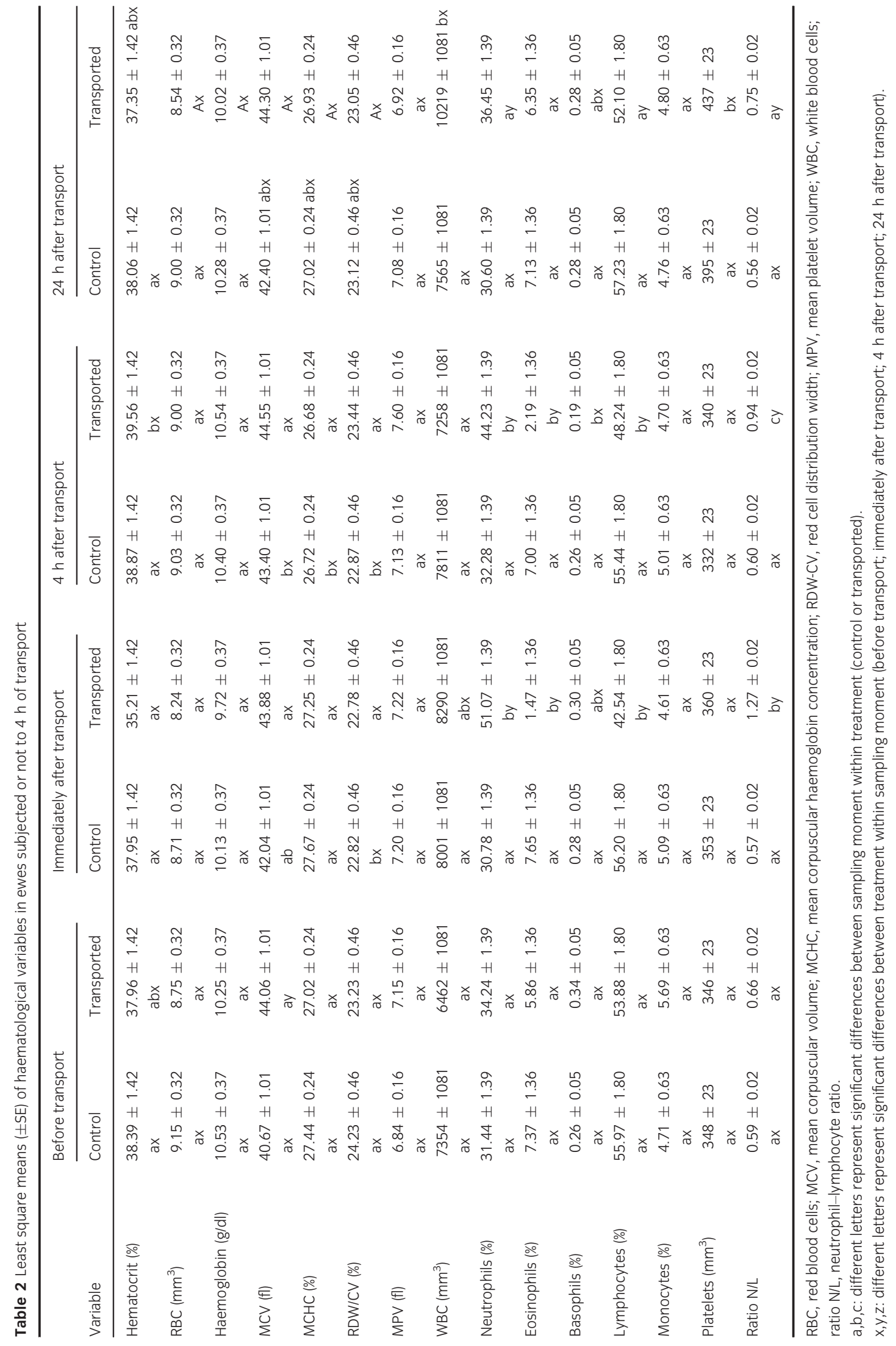




\section{Behavioural and live weight measurements}

The results from 180 min of scan sampling are summarized in Table 3. Control ewes spent more time walking $(46.8 \%, \quad p<0.01)$, drinking $(234.6 \%$, $\mathrm{p}<0.05)$ and eating $(154 \%, \mathrm{p}<0.001)$. In the case of the behaviours recorded after unloading (Table 4), the first behaviour was eating $(86 \%)$, and then drinking $(43 \%)$. After that period, they finally started to lie down $(25 \%)$. The average $( \pm S E)$ of the post-transport live weight was $46.74 \pm 1.74 \mathrm{~kg}$ (transported ewes) and $47.89 \pm 1.74 \mathrm{~kg}$ (control ewes). The average $( \pm \mathrm{SE})$ differences in live weight between pre-transport and post-transport weight in transported ewes were $-0.98 \pm 0.18 \mathrm{~kg}$ while control ewes gained some weight during the same period of time $(+0.24 \pm 0.18 \mathrm{~kg})$.

\section{Discussion}

In general, transported ewes lost weight compared to control ewes and had higher levels of cortisol, glucose, NEFA, N/L ratio, and body temperature profiles related to stress, as well as differences in some behavioural patterns. In this context, the new information from this study would suggest modifications to logistic planning and route optimization to minimize the biological cost in live journeys under study conditions. During transport, temperature and humidity can change abruptly, which may have an effect on animal welfare (Villarroel et al., 2011). The THI is used to assess environmental conditions that may cause thermal stress problems in sheep: normal, $\leq 74$; alert,

Table 3 Behaviours rates (\%) observed during 180 min of scan sampling in ewes transported or not transported (control) by road for $4 \mathrm{~h}$ (scan sampling starts $50^{\prime}$ after unloading)

\begin{tabular}{lrrl}
\hline & \multicolumn{1}{l}{$\begin{array}{l}\text { Not transported } \\
\text { (control) }\end{array}$} & Transported & p Value \\
\hline Eating & $17.48 \pm 3.22$ & $44.40 \pm 3.22$ & 0.001 \\
Drinking & $0.52 \pm 0.09$ & $1.74 \pm 0.09$ & 0.05 \\
Walking & $10.83 \pm 1.61$ & $15.90 \pm 1.61$ & 0.028 \\
Lying down & $70.97 \pm 3.48$ & $37.93 \pm 3.48$ & 0.028 \\
\hline
\end{tabular}

Table 4 Average times in minutes to perform the main behaviours after a 4-h journey by road transport in ewes

\begin{tabular}{lrrrrrr}
\hline Behaviour & Mean & SE & Min & Max & Range & CV (\%) \\
\hline Eating & 8.25 & 1.54 & 0.25 & 16.02 & 15.77 & 86 \\
Drinking & 52.06 & 3.58 & 5.30 & 127 & 121.70 & 43 \\
Lying down & 118.63 & 5.63 & 51.04 & 166 & 114.96 & 25 \\
\hline
\end{tabular}

75-78; danger, 79-83; emergency, $\geq 84$ (Silanikove, 2000). In this study, THI values fell within the danger category in transported ewes. High temperatures during transport cause stress and dehydration, and after loading, the humidity and temperature within the truck rise quickly (Miranda-de la Lama et al., 2011 ). This stimulates evaporative heat loss in the animals by panting and sweating, creating a microclimate that favours dehydration (Caulfield et al., 2014).

\section{Thermophysiological measurements}

Inspired by precision agriculture, a farming practice of precision livestock farming is under development (Scholten et al., 2013). In this context, radio telemetry has provided the method of choice for stress-free recording of core body temperature in recent years (Dallmann et al., 2006). However, IBUTTON THERMOCHRON ${ }^{\circledR}$ require no telemetric recording devices and have therefore low set-up costs, are reusable, have a reasonable temperature resolution $\left(0.1{ }^{\circ} \mathrm{C}\right)$ and temperature range of $-40{ }^{\circ} \mathrm{C}$ to $+85^{\circ} \mathrm{C}$, in contrast to most telemetric systems, and allow synchronous measuring of corporal temperature from several animals per truck. The results of the study show that the internal body temperature of transported ewes rose during the journey and only started to decrease after unloading. It is possible that the physical activity associated with vehicle movements and vibrations during transport could have added to the increase in core temperature observed in the transported group (Miranda-de la Lama et al., 2011). However, the increases can be labelled as hyperthermia as the core temperature was within the range of hyperthermia reported for stressed sheep during shearing (Sanger et al., 2011) and transportation (Ingram et al., 2002). Furthermore, hyperthermia, demonstrated through a conditioned rise in body temperature in response to unpleasant events, is thought to be evidence of the phylogenetic development of emotions (Proctor and Carder, 2015). Hyperthermia by stress is accompanied by elevations in plasma ACTH, cortisol and glucose levels. Furthermore, the cardiovascular system is stimulated, and both brain and pituitary opioids increase in terms of release (Dallmann et al., 2006).

\section{Haematological and biochemical measurements}

Cortisol is an important physiological marker commonly used to measure the stress response in sheep transport studies (Krawczel et al., 2007), and basal plasma cortisol concentrations may be useful in predicting how an animal will respond to stimuli and 
thus provide useful information about an animal welfare status (Lepherd et al., 2011). Previous studies have shown that cortisol levels tend to rise during and after transport in sheep (Ekiz et al., 2013). In this study, cortisol levels immediately after transport were twice the pre-transport levels and two times higher than controls, at the same sampling time. Broom et al. (1996) found that plasma cortisol levels were higher in transported sheep up to $3 \mathrm{~h}$ after transport, compared with controls. Depending on the transport time, cortisol levels may continue to increase after unloading, but then tend to decrease when animals are resting (Bórnez et al., 2009). In our case, the cortisol levels of transported ewes were similar to controls $4 \mathrm{~h}$ after unloading. The results for cortisol are consistent with the observed glucose levels. During stress, the increase in plasma glucose is preceded by an increase in cortisol, due to the gluconeogenic effect of this hormone (Miranda-de la Lama et al., 2012).

Glucose levels increased in transported ewes immediately after transport, reaching almost twice the levels of controls. Elevated NEFA concentrations are a lipolytic response to adrenaline release, are a good indicator of body fat utilization in stressful transport and also followed the same pattern as cortisol and glucose, increasing immediately after the journey. Glucose and NEFA also returned to control values $4 \mathrm{~h}$ after transport. There is evidence indicating that live weight declines and plasma-free fatty acids and urea rise during transport, demonstrating that glucose reserves are limiting, so body fat and protein have to be mobilized to provide energy instead (Fisher et al., 2010). Any process, which increases protein catabolism, will tend to result in increased levels of serum urea (Knowles et al., 1994). The increase of urea concentrations in the transported ewes was probably due to physical exercise during journey, to the effects of glucocorticoids on protein catabolism, and also to food deprivation (Montané et al., 2002). Kadim et al. (2007) found more uric acid and lower total plasma protein in transported animals, but we found no differences in the latter. Stress can also result in plasma mineral imbalance, especially due to a reduction in sodium, potassium, calcium and phosphorus (Caroprese et al., 2012). Our results show a decrease in phosphorus and calcium after transport, with lower calcium in transported sheep, but phosphorus levels remained higher compared with control animals.

Haptoglobin levels increased significantly in both treatments $24 \mathrm{~h}$ after transport, and there were no significant differences between treatments. These results may be a side effect of having taken the first blood sample 48 h earlier, demonstrating the extreme sensi- tivity of this indicator, which complicates its application under stressful but normal handling routines. Another sampling $48 \mathrm{~h}$ after transport may be needed to test possible differences between treatments regarding haptoglobin increase due to road transport alone. Piccione et al. (2012) found that haptoglobin increased during the resting time after transport compared to pre-transport values, but this increase was only significant after $48 \mathrm{~h}$ of resting (after road transport).

The number of neutrophils increased, while the number of eosinophils and lymphocytes decreased in transported ewes, but not in control group. A possible explanation could be related during the first stage of the stress response or alarm phase, where catecholamines may be responsible for the initial neutrophilia and lymphocytosis (Montané et al., 2002). In the second stage of stress response or resistance phase, cortisol contributes further to neutrophilia, but may cause a lymphopenia and eosinopenia, thereby increasing the N/L ratio (Miranda-de la Lama et al., 2012). The observed changes in the $\mathrm{N} / \mathrm{L}$ ratio could be explained in terms of changes in cell trafficking and reservoir site (Zapata et al., 2004). Even if the animals have a complex repertoire of adaptive and homoeostatic (physiological and behavioural) mechanisms for dealing with the challenges of continually fluctuating environments such as transport, our results indicate that a short exposure $(4 \mathrm{~h})$ to transport can increase the probability of health problems and may affect the ability of the adult ewes to cope a novel environment upon arrival to a new farm or winter shelter. Finally, high WBC values as well as the increase in platelet numbers $24 \mathrm{~h}$ after transport have been associated with strenuous exercise during handling, loading, journey and loading (Miranda-de la Lama et al., 2010).

\section{Behavioural and live weight measurements}

In the current study, after unloading, transported ewes ate before they drank, and waited for a considerable period of time before resting. This agrees with the results of Knowles et al. (1994), who found that, after unloading, sheep were very alert, showing great interest in food, and only secondarily interested in drinking and resting. Many studies have analysed the most appropriate rest stop durations for sheep, suggesting that if the stop is too short, they will not have time to drink (Krawczel et al., 2007). The results of the present study support those findings as the sheep only began to drink 40 min after they had begun eating. The European regulation on the protection of animals 
during transport (Chapter V) says that adult sheep 'must, after $14 \mathrm{~h}$ of travel, be given a rest period of at least $1 \mathrm{~h}$ sufficient for them in particular to be given liquid and if necessary feed. After this rest period, they may be transported for a further $14 \mathrm{~h}^{\prime}$. Our results disagree with this recommendation as, if the goal of stopping is to hydrate the animals, $\mathrm{l} \mathrm{h}$ is not enough to give all the animals the opportunity to access water troughs.

Altered patterns of feeding, drinking and resting are the most common behavioural response in sheep to transport operations (Nielsen et al., 2011). Although the same restriction for food (straw and concentrate) was applied $1 \mathrm{~h}$ before transport until unloading for both treatments, there existed differences in behavioural patterns between the two groups. The results of this study show that transported animals rested significantly less than the control group, which agrees with Messori et al. (2015), who reported higher rest levels in controls compared with transported ewes. The resting period after transportation is known to be efficient to decrease cortisol levels and consequently recover from the stress caused by the journey; however, the length of the resting period could be to shortly reduce stress (Da Cunha Leme et al., 2012). If resting behaviour is a positive indicator of welfare (Boissy et al., 2007), we can conclude (solely from the behavioural perspective) that transported sheep were more stressed.

It is recognized that transportation will decrease the body weight of animals depending on the fasting time and water deprivation, and sheep may lose between $5 \%$ and $7 \%$ of their body weight after a journey (Zhong et al., 2011). In this study, the weight loss was approximately $2 \%$, which is within the acceptable limits for this type of animal and season of the year. Other studies have also found significant losses of body weight in a group of sheep after $8 \mathrm{~h}$ of transport (Zhong et al., 2011) and even after $4 \mathrm{~h}$ (RajeshKumar et al., 2003). However, it is important to remark that our study was performed with a smallsized indigenous breed, well adapted to hard living conditions in extensive production systems (Pascual-
Alonso et al., 2014). Those characteristics give them a great flexibility in adapting to environmental changes. The decrease in body weight could be due to a loss of gut contents and body water by increased defecation and urination (Rajesh-Kumar et al., 2003).

\section{Conclusions}

This study demonstrates that even short journeys by road can induce behavioural, physiological and thermophysiological responses indicative of significant stress, leading to live weight shrinkage that may jeopardize farmer income. Changes in body temperature during transport as a result of the stress response can be used to provide information to assist in determining ewe welfare. The results of this study validated the use of IBUTTON THERMOCHRON ${ }^{\circledR}$ data loggers for monitoring the stress response during transport. Improving animal welfare requires developing new knowledge and methods, particularly with respect to less-invasive welfare indicators during livestock transport. Those improvements should be aimed at improving transport to prioritize animal welfare, in addition to the promotion of legislation based on scientific evidence. Transport surveillance systems need to be developed that integrate information regarding animal identification, unloading point and time, lorry temperature, and animal thermophysiological stress responses (especially with respect to evaluating journey quality).

\section{Acknowledgements}

This research was financed by the Spanish Ministry of Economy \& Competitiveness (MINECO), Project AGL-2009/10794. Thanks to the Autonomous Community of La Rioja for the PhD scholarship for $\mathrm{M}$. Pascual-Alonso and to MINECO for the research scholarship for Personnel Training (FPI) for Mrs. Lorena Aguayo-Ulloa. G.C. Miranda-de la Lama is a member of the National Researches System of the National Council on Science and Technology (SNICONACyT), level 2.

\section{References}

Boissy, A.; Manteuffel, G.; Jensen, M. B.; Moe, R. O.; Spruijt, B.; Keeling, L. J.; Winckler, C.; Forkman, B.; Dimitrov, I.; Langbein, J.; Bakken, M.; Veissier, I.; Aubert, A., 2007: Assessment of positive emotions in animals to improve their welfare. Physiology $\theta$ Behavior 92 , 375-397.
Bórnez, R.; Linares, M. B.; Vergara, H., 2009: Hematological, hormonal and biochemical parameters in lamb: effect of age and blood sampling time. Livestock Science 121, 200-206.

Broom, D. M.; Goode, J. A.; Hall, S. J. G.; Lloyd, D. M.; Parrott, R. F., 1996: Hormonal and physiological effects of a 15 hour road journey in sheep: comparison with the response to loading, han- dling and penning in the absence of transport. British Veterinary Journal 152, 593-604.

Caroprese, M.; Albenzio, M.; Bruno, A.; Annicchiarico, G.; Marino, R.; Sevi, A., 2012: Effects of shade and flaxseed supplementation on the welfare of lactating ewes under high ambient temperatures. Small Ruminant Research 102, 177185. 
Caulfield, M.; Cambridge, H.; Foster, S. F.; McGreevy, P. D., 2014: Heat stress: a major contributor to poor animal welfare associated with long-haul live export voyages. The Veterinary Journal 199, 223-228

Chacón, G.; Garcia-Belenguer, S.; Illera del Portal, J. C.; Palacio, J., 2004: Validation of an EIA technique for the determination of salivary cortisol in cattle. Spanish Journal of Agricultural Research 2, 45-51.

Da Cunha Leme, T. M.; Titto, E. A. L.; Titto, C. G.; Amadeu, C. C. B.; Neto, P. F.; Vilela, R. A.; Pereira, A. M. F., 2012: Influence of transportation methods and pre-slaughter rest periods on cortisol level in lambs. Small Ruminant Research 107, 8-11.

Dallmann, R.; Steinlechner, S.; von Hörsten, S.; Karl, T., 2006: Stressinduced hyperthermia in the rat: comparison of classical and novel recording methods. Laboratory animals 40, 186193.

Ekiz, B.; Ergül-Ekiz, E.; Yalcintan, H.; Yilmaz, A.; Kocak, O.; Gunes, H., 2013: Effect of ram-ewe mixed transportation on certain welfare parameters in Red Karaman and Imroz sheep. Journal of the Faculty of Veterinary Medicine Istanbul University 39, 155-167.

European Commission, 2006: Commission working document on a community action plan on the protection and welfare of animals 2006-2010. Available in. http://europa.eu.int/comm/food/animal/welfare/work_doc_strategic_basis230106_en.pdf

Fisher, A. D.; Colditz, I. G.; Lee, C.; Ferguson, D. M., 2009: The influence of land transport on animal welfare in extensive farming systems. Journal of Veterinary Behaviour: Clinical Applications and Research 4, 157-162.

Fisher, A. D.; Niemeyer, D. O.; Lea, J. M.; Lee, C.; Paull, D. R.; Reed, M. T.; Ferguson, D. M., 2010: The effects of 12, 30, or $48 \mathrm{~h}$ of road transport on the physiological and behavioral responses of sheep. Journal of Animal Science $\mathbf{8 8}$, 2144-2152.

Gebresenbet, G.; Bosona, T. G.; Ljungberg, D.; Aradom, S., 2011: Optimisation analysis of large and small-scale abattoirs in relation to animal transport and meat distribution. Australian Journal of Agricultural Engineering 2, 31-39.

Hilmer, S.; Algara, D.; Neckc, D.; Schleucher, E., 2010: Remote sensing of physiological data: impact of long term captivity on body temperature variation of the feral cat (Felis catus) in Australia, recorded via Thermochron iButtons. Journal of Thermal Biology 35, 205-210.

Ingram, J.; Cook, C.; Harris, P., 2002: The effect of transport on core and peripheral body temperatures and heart rate of sheep. Animal Welfare 11, 103112.

Jones, B.; Tensen, M. C., 2009: RSPCA Australia scientific seminar 2008 animals in transit: the journey ahead. Journal of Veterinary Behaviour: Clinical Applications and Research 4, 145-147.

Kadim, I. T.; Mahgoub, O.; Alkindi, A. Y.; Al-Marzooqi, W.; Al-Saqri, N. M.; Almaney, M.; Mahmoud, I. Y., 2007: Effect of transportation at high ambient temperatures on physiological responses, carcass and meat quality characteristics in two age groups of Omani sheep. Asian-Australasian Journal of Animal Sciences 20, 424-431.

Knowles, T. G.; Warriss, P. D.; Brown, S. N.; Kestin, S. C., 1994: Long distance transport of export lambs. The Veterinary Record 134, 107-110.

Krawczel, P. D.; Friend, T.; Caldwell, D. J.; Archer, G.; Ameiss, K., 2007: Effects of continuous versus intermittent transport on plasma constituents and antibody response of lambs. Journal of Animal Science 85, 468-476.

Lepherd, M. L.; Canfield, P. J.; Hunt, G. B.; Thomson, P. C.; Bosward, K. L., 2011: Assessment of the short-term systemic effect of and acute phase response to mulesing and other options for controlling breech flystrike in Merino lambs. Australian Veterinary Journal 89 , 19-26.

Liu, H. W.; Zhong, R. Z.; Zhou, D. W.; Sun, H. X.; Zhao, C. S., 2012: Effects of lairage time after road transport on some blood indicators of welfare and meat quality traits in sheep. Journal of Animal Physiology and Animal Nutrition 96, 1127-1135.

Messori, S.; Pedernera-Romano, C.; Magnani, D.; Rodriguez, P.; Barnard, S.; Dalmau, A.; Velarde, A.; Dalla Villa, P., 2015: Unloading or not unloading? Sheep welfare implication of rest stop at control post after a 29 h transport. Small Ruminant Research 130, 221-228.

Miranda-de la Lama, G. C.; Rivero, L.; Chacón, G.; Garcia-Belenguer, S.; Villar- roel, M.; María, G. A., 2010: Effect of the pre-slaughter logistic chain on some indicators of welfare in lambs. Livestock Science 128, 52-59.

Miranda-de la Lama, G. C.; Monge, P.; Villarroel, M.; Olleta, J. L.; GarciaBelenguer, S.; María, G. A., 2011 : Effects of road type during transport on lamb welfare and meat quality in dry hot climates. Tropical Animal Health and Production 43, 915-922.

Miranda-de la Lama, G. C.; SalazarSotelo, M. I.; Perez-Linares, C.; Figueroa-Saavedra, F.; Villarroel, M.; Sañudo, C.; Maria, G. A., 2012: Effects of two transport systems on lamb welfare and meat quality. Meat Science $\mathbf{9 2 ,}$ 554-561.

Miranda-de la Lama, G. C.; Villarroel, M.; María, G. A., 2014: Livestock transport from the perspective of the pre-slaughter logistic chain: a review. Meat Science 98, 9-20.

Mitchell, M. A.; Kettlewell, P. J., 2008: Engineering and design for vehicles for long distance road transport of livestock (ruminants, pigs and poultry). Veterinaria Italiana 44, 201-213.

Montané, J.; Marco, I.; López-Olvera, J.; Manteca, X.; Lavin, S., 2002: Transport stress in roe deer (Capreolus capreolus): effect of a short-acting antipsychotic. Animal Welfare 11, 405-418.

Nielsen, B. L.; Dybkjær, L.; Herskin, M. S., 2011: Road transport of farm animals: effects of journey duration on welfare. Animal 5, 415-427.

Pascual-Alonso, M.; Miranda-de la Lama, G. C.; Aguayo-Ulloa, L.; Villarroel, M.; Alierta, S.; Maria, G. A., 2014: Influence of coat colour on Chamarita sheep phenotypes, behaviour, welfare and performances. Animal Genetic Resources 54, 179-184.

Pedernera-Romano, C.; Ruiz de la Torre, J. L.; Badiella, L.; Manteca, X., 2010: Effect of perphenazine enanthate on openfield test behaviour and stress-induced hyperthermia in domestic sheep. Pharmacology, Biochemistry and Behavior $\mathbf{9 4}$, 329-332.

Piccione, G.; Casella, S.; Giannetto, C.; Giudice, E.; Fazio, F., 2012: Utility of acute phase proteins as biomarkers of transport stress in ewes. Small Ruminant Research 107, 167-171.

Piccione, G.; Rizzo, M.; Casella, S.; Marafioti, S.; Fazio, F., 2014: Application of the iButton ${ }^{\circledR}$ for measurement of the rumen temperature circadian rhythms 
in lambs. Biological Rhythm Research 45 , 375-381.

Proctor, H. S.; Carder, G., 2015: Nasal temperatures in dairy cows are influenced by positive emotional state. Physiology $\theta$ Behavior 138, 340-344.

Rajesh-Kumar, B.; Muralidharan, M. R.; Ramesh, V.; Arunachalam, S.; Sivakumar, T., 2003: Effect of transport stress on economic loss in sheep. Indian Journal of Animal Research 37, 54-56.

Roznik, E. A.; Alford, R., 2012: Does waterproofing thermochron iButton data loggers influence temperature readings? Journal of Thermal Biology 37, 260-264.

Sanger, M. E.; Doyle, R. E.; Hinch, G. N.; Lee, C., 2011: Sheep exhibit a positive judgement bias and stress-induced hyperthermia following shearing. Applied Animal Behaviour Science 131, 94-103.

SAS, 1998: User's guide: Statistics. Release 6.03. Statistical Analysis System, Cary, NC, USA

Scholten, M. T.; De Boer, I. J. M.; Gremmen, B.; Lokhorst, C., 2013: Livestock farming with care: towards sustainable production of animal-source food. NJAS-Wageningen Journal of Life Sciences 66, 3-5.

Silanikove, N., 2000: Effects of heat stress on the welfare of extensively managed domestic ruminants. Livestock Production Science 67, 1-18.

Villarroel, M.; Barreiro, P.; Kettlewell, P.; Farish, M.; Mitchell, M., 2011: Time derivatives in air temperature and enthalpy as non-invasive welfare indicators during long distance animal transport. Biosystems Engineering 110, 253-260.

Zapata, B.; Gimpel, J.; Bonacic, C.; González, B. A.; Riveros, J. L.; Ramírez, A. M.; Bas, F.; Macdonald, D. W., 2004: The effect of transport on cortisol, glucose, heart rate, leukocytes and body weight in captive-reared guanacos (Lama guanicoe). Animal Welfare 13, 439-444.

Zhong, R. Z.; Liu, H. W.; Zhou, D. W.; Sun, H. X.; Zhao, C. S., 2011: The effects of road transportation on physiological responses and meat quality in sheep differing in age. Journal of Animal Science 89, 3742-3751. 